\title{
In vivo detection of Escherichia coli type 1 fimbrial expression and phase variation during experimental urinary tract infection
}

\author{
Carsten Struve and Karen Angeliki Krogfelt
}

Department of

Gastrointestinal Infections,

Statens Serum Institut,

5 Artillerivej, 2300

Copenhagen 5, Denmark
Author for correspondence: Karen Angeliki Krogfelt. Tel: +45 3268 3745. Fax: +45 32683873. e-mail:kak@ssi.dk

\begin{abstract}
Adhesion mediated by fimbriae is thought to play an important role in the pathogenesis of urinary tract infections (UTI) by Escherichia coli. The majority of clinical isolates of $E$. coli from UTI are able to express type 1 fimbriae. However, the importance of these fimbriae as a virulence factor has been controversial. To investigate the expression of type 1 fimbriae in vivo during UTI, mice were transurethrally infected with uropathogenic $E$. coli C175-94 and type 1 fimbrial expression was determined directly by two independent methods at $\mathbf{2} \mathrm{h}, \mathbf{1} \mathrm{d}$ and $3 \mathrm{~d}$ after infection. By use of an assay combining in situ rRNA hybridization and immunofluorescence, all bacterial cells detected in urine, bladders and kidneys from mice sacrificed 1 and $3 \mathbf{d}$ after onset of infection were found to express type 1 fimbriae. In contrast, the majority of cells in the suspension used for infection of mice and specimens from mice sacrificed $2 \mathrm{~h}$ after inoculation were found to be non-fimbriated. Similar results were obtained with a PCR assay revealing the orientation of the invertible promoter driving the transcription of type 1 fimbrial genes. Whilst the promoter in both ON and OFF positions could be amplified from the suspension used for infection and specimens from mice sacrificed $2 \mathrm{~h}$ after inoculation, at 1 and $3 \mathrm{~d}$ after onset of infection only the promoter in the ON orientation could be amplified. These results show that introduction of $E$. coli C175-94 into the mouse urinary tract leads to markedly enhanced expression of type 1 fimbriae.
\end{abstract}

Keywords: type 1 fimbriae, phase variation, urinary tract infection, in situ hybridization, immunofluorescence

\section{INTRODUCTION}

Escherichia coli is the pathogen responsible for most cases of uncomplicated urinary tract infections (UTI), one of the most frequent human infectious disorders (Sobel, 1991). Fimbriae mediate the ability of E. coli cells to adhere to the uroepithelium, thereby resisting elimination by the flow of urine. Adhesion is therefore considered an important step in the pathogenesis of UTI (Reid \& Sobel, 1987). Among the different types of fimbrial adhesins, $P$ fimbriae have been identified as an important virulence factor among uropathogenic E. coli strains (Donnenberg \& Welch, 1996). The role of type 1 fimbriae in pathogenesis has been less clear, especially due to the ubiquity of the fimbriae, as they are found on

Abbreviation: UTI, urinary tract infections. approximately $70 \%$ of all E. coli isolates and most Pfimbriated E. coli strains also possess type 1 fimbriae (Orndorff \& Bloch, 1990; Hagberg et al., 1981). Furthermore, in vitro adherence studies of either purified type 1 fimbriae or type-1-fimbriated E. coli strains to formaldehyde-fixed human tissue and to exfoliated epithelial cells from the urine gave contradictory results (Fujita et al. 1989; Virkola 1987; Ørskov et al. 1980).

Recent studies of UTI with animal models show that type-1-fimbriated E. coli cells are better colonizers of the urinary tract than their isogenic mutants (Connell et al., 1996; Langermann et al., 1997; Sokurenko et al., 1998; Mulvey et al., 1998).

Type 1 fimbriae mediate adhesion to structures containing D-mannose, but have also been shown to mediate binding to non-glycosylated peptide epitopes (Sokurenko et al., 1994). The fim gene cluster, consisting 
of nine genes, includes fimA, which encodes the major fimbrial subunit (Klemm \& Krogfelt, 1994). The expression of type 1 fimbriae is characteristically phasevariable; i.e. individual cells can switch between fimbriated and non-fimbriated states. The phase variation is mediated by a 314 bp invertible DNA element (phase switch) containing the promoter of fim $A$ (Abraham et al., 1985). When the switch is in one position $(\mathrm{ON})$ the promoter drives the transcription of fim $A$ and fimbriae are produced, whilst inversion of the switch to the OFF position leads to arrest of transcription and non-fimbriated cells. Two recombinases encoded by the fim cluster, FimB and FimE, mediate the inversion of the invertible element (Klemm, 1986). Several elements regulating the expression of FimB and FimE and the sensitivity of the invertible element towards switching, including environmental factors such as temperature and growth media, have been identified (Old \& Duguid, 1970; Schwan et al., 1992; Blomfield et al., 1993; Gally et al., 1993; Newman et al., 1994; Olsen et al., 1998).

Only a few studies have investigated the expression of type 1 fimbriae in vivo during UTI. These studies have either used indirect methods, i.e. determined fimbrial expression in bacteria isolated from specimens from infected animals after growth in vitro (Hagberg et al. 1983; Schaeffer et al. 1987), or investigated bacterial cells in urine collected from patients suffering from UTI (Ofek et al., 1981; Harber et al., 1982; Ljungh \& Wadström, 1983; Pere et al., 1987; Kisielius et al., 1989). Hultgren et al. (1985) investigated the expression of type 1 fimbriae in urine and bladder lavages from infected mice by electron microscopy and in a recent study, a PCR assay was used to determine the orientation of the phase switch in specimens from infected mice (Lim et al., 1998).

In the present study, we used two independent assays to detect directly the expression of type 1 fimbriae in vivo during experimental UTI: a combination of in situ rRNA hybridization and immunofluorescence for detection of fimbrial expression, and a PCR assay for determination of the orientation of the phase switch of E. coli bacteria in tissues of the urinary tract to establish the kinetics of phase variation of the fimbriae during infection.

\section{METHODS}

Bacterial strains and media. E. coli C175-94, a clinical isolate from a patient with UTI, was used throughout the study. It belongs to serotype O8: K48: $\mathrm{H} 9$, expresses type 1 fimbriae but not $\mathrm{P}$ or $\mathrm{S}$ fimbriae and does not produce haemolysin. Yersinia enterocolitica SSI 7558 serotype O3 was used as control for specificity in the development of the combined in situ hybridization and immunofluorescence assay. Bacteria were grown in either L broth (Statens Serum Institut; SSI) or on bromothymol blue agar plates (SSI).

Preparation of inoculum for infection of mice. Bacteria were grown in filter-sterilized human urine and passaged three times as described by Sharma et al. (1991). They were then incubated overnight at $37^{\circ} \mathrm{C}$ with shaking, centrifuged at
$6500 \mathrm{~g}$ for $10 \mathrm{~min}$ and the pellet suspended in PBS $(130 \mathrm{mM}$ $\mathrm{NaCl}, 8 \mathrm{mM} \mathrm{Na}_{2} \mathrm{HPO}_{4}, 2 \mathrm{mM} \mathrm{KH} \mathrm{PO}_{4}, \mathrm{pH} \mathrm{7.4)}$ (SSI) to a concentration of approximately $10^{10}$ c.f.u. $\mathrm{ml}^{-1}$.

Mouse model of ascending UTI. Outbred female albino mice, Ssc: CF1, $30 \pm 2 \mathrm{~g}$ (SSI) were used. The mice were anaesthetized by intraperitoneal administration of $0.08 \mathrm{ml}$ mixture of Hypnorm $\left(0 \cdot 315 \mathrm{mg}\right.$ fentanyl citrate $\mathrm{ml}^{-1}$ and $10 \mathrm{mg}$ fluanison $\mathrm{ml}^{-1}$; Janssen Animal Health) and diazepam (5 mg $\mathrm{ml}^{-1}$ ) in a ratio of $10: 3$. Twenty-four mice were inoculated transurethrally with $0.05 \mathrm{ml}$ of the bacterial suspension by use of plastic catheters (SSI). As control, six mice were inoculated with PBS. The catheter was carefully pushed in horizontally through the urethral orifice until it reached the top of the bladder, whereupon the bacterial suspension was slowly injected into the bladder. The catheter was immediately removed after inoculation and the mice subjected to no further manipulations until sacrifice.

The mice were sacrificed in groups of 10 by cervical dislocation $2 \mathrm{~h}, 1 \mathrm{~d}$ and $3 \mathrm{~d}$ after inoculation. Urine was collected from each mouse by gentle compression of the abdomen and then the bladder and kidneys were removed aseptically. The organs were bisected and one half of each specimen was either used for preparation of tissue sections or as sample for PCR. The other half was homogenized manually in $500 \mu$ l collagenase solution (500 units $\mathrm{ml}^{-1}$; Sigma) and serially diluted for quantitative culture on bromthymol blue agar plates (SSI).

Preparation of samples for combined in situ hybridization and immunofluorescence assay. Immediately after death, bladders and kidneys from inoculated mice were transferred to a phosphate-buffered $4 \%$ solution of formalin. The fixed organs were then dehydrated and embedded in paraffin prior to preparation of $5 \mu \mathrm{m}$ thick sections mounted on glass slides. Prior to hybridization, paraffin was recovered from the sections by treatment with xylene 3 times for $10 \mathrm{~min}$ followed by 10 min dehydration in $96 \%$ ethanol. After drying at room temperature, the sections were circumscribed with a hydrophobic pen (Dako).

Urine from inoculated mice, inoculum suspension and overnight cultures of C175-94 was centrifuged at $6500 \mathrm{~g}$; the pellets were resuspended in $4 \%$ formalin solution and kept at $4{ }^{\circ} \mathrm{C}$ for $20 \mathrm{~min}$. The fixed cells were isolated by centrifugation and washed three times with PBS. The washed cells were suspended in PBS and $15 \mu \mathrm{l}$ samples of the suspension were then transferred to wells in a poly-L-lysine-coated 6-well slide and left to dry at room temperature.

Oligonucleotide probe and antisera. Probe EC1531 (5'CACCGTAGTGCCTCGTCATCA-3') specific for E. coli $23 \mathrm{~S}$ rRNA, labelled with CY3, was used for visualization of E. coli cells as previously described (Poulsen et al., 1994).

For detection of expression of type 1 fimbriae, rabbit antiserum raised against purified type 1 fimbriae was used (Krogfelt \& Klemm, 1988). Rabbit antiserum against Y. enterocolitica $\mathrm{O} 3$ antigen (SSI) was used for detection of $Y$. enterocolitica cells. FITC-conjugated swine anti-rabbit immunoglobulin (Dako) was used as secondary antibody.

Combined in situ hybridization and immunofluorescence assay. Hybridization was performed by adding hybridization solution $(10 \%$ formamide, $0 \cdot 1 \mathrm{M}$ Tris $\mathrm{pH} 7 \cdot 2,0 \cdot 9 \mathrm{M} \mathrm{NaCl})$ containing $2.5 \mathrm{ng}$ probe EC $1531 \mathrm{ll}^{-1}$ to tissue sections or slide wells. After incubation in humidified chambers overnight at $37^{\circ} \mathrm{C}$, the slides were washed in washing solution $(0 \cdot 1 \mathrm{M}$ Tris $\mathrm{pH} 7 \cdot 2,0 \cdot 9 \mathrm{M} \mathrm{NaCl}$ ) for $15 \mathrm{~min}$, followed by incubation with antibody diluted in washing solution containing $2.5 \mathrm{ng}$ probe EC1531 $\mu^{-1}$ for $45 \mathrm{~min}$. The slides were then washed 3 times 
for $5 \mathrm{~min}$ in washing solution before incubation with secondary antibody diluted in washing solution containing $2.5 \mathrm{ng}$ probe EC1531 $\mu \mathrm{l}^{-1}$ for $45 \mathrm{~min}$. After washing again 3 times for $5 \mathrm{~min}$ in washing solution, the slides were briefly rinsed in distilled water and left to dry at room temperature. Cover slips were mounted with Vectrashield (Vector Laboratories) and the slides observed at $\times 1000$ magnification with an Olympus $\mathrm{BH} 2-\mathrm{RFC}$ fluorescence microscope. Green and blue excitation filters were used for determination of the total number of $E$. coli cells and the number of cells expressing type 1 fimbriae, respectively.

For the inoculum suspension and each urine sample, three different slide wells were evaluated. The total number of cells in three microscope fields, typically 50-300 cells, was counted and compared to the number of cells expressing type 1 fimbriae. For each infected organ, 10 different tissue sections were evaluated.

Preparation of samples for PCR. Inoculum suspension, urine, bladders and kidneys sampled for PCR were collected in Eppendorf tubes containing $500 \mu \mathrm{l}$ PBS, immediately boiled for $5 \mathrm{~min}$ and kept at $-80{ }^{\circ} \mathrm{C}$ until use. After thawing, the organs were homogenized manually. Organ homogenates, urine samples and inoculum suspension were boiled for 20 min, centrifuged at $10000 \mathrm{~g}$ for $15 \mathrm{~min}$ and the supernatants were removed and kept at $-20{ }^{\circ} \mathrm{C}$ until use as templates for PCR reaction.

PCR amplification and restriction enzyme digestion. PCR primers A (5'-GAGAAGAGGTTTGATTTAACTTATTG$\left.3^{\prime}\right)$ and B (5'-AGAGCCGCTGTAGAACTGAGG-3') were used for amplification of a 559 bp DNA element covering the fim switch region as described by Roesch \& Blomfield (1998). The Expand High Fidelity PCR System (Boehringer Mannheim) was used for the PCR reaction. The reaction mixtures were prepared according to the instructions of the manufacturer in a total of $50 \mu \mathrm{l} 1.5 \mathrm{mM} \mathrm{MgCl}_{2}$ solution containing $2 \mu \mathrm{l}$ template. The reaction conditions were as follows: an initial denaturation at $94{ }^{\circ} \mathrm{C}$ for $1 \mathrm{~min}$; followed by 40 cycles of denaturation at $94{ }^{\circ} \mathrm{C}$ for $1 \mathrm{~min}$, annealing at $58{ }^{\circ} \mathrm{C}$ for $70 \mathrm{~s}$ and elongation at $72{ }^{\circ} \mathrm{C}$ for $70 \mathrm{~s}$. The reaction was completed by a final elongation step at $72{ }^{\circ} \mathrm{C}$ for $3 \mathrm{~min}$.

The PCR products were digested by the restriction endonuclease HinfI (New England Biolabs) according to the manufacturer's instructions. The digested PCR products were electrophoresed in 3\% agarose gels, stained by ethidium bromide and visualized by UV illumination.

Growth in mouse urine, bladder mucus and L broth. Urine was collected from six mice, sterilized by UV illumination and dialysed against $0.9 \% \mathrm{NaCl}$ overnight.

Mucus was scraped from the bladders of six mice using a rubber spatula. Dialysed urine, crude mucus suspension and $\mathrm{L}$ broth were inoculated with E. coli C175-94 corresponding to a concentration of $10^{4}$ c.f.u. $\mathrm{ml}^{-1}$ and incubated at $37^{\circ} \mathrm{C}$ overnight. The experiment was repeated three times.

\section{RESULTS}

\section{Experimental UTI}

Mice were successfully infected with E. coli C175-94 as evaluated by viable counts of bacteria in kidneys from mice sacrificed $2 \mathrm{~h}, 1 \mathrm{~d}$ and $3 \mathrm{~d}$ after inoculation. Two hours after inoculation, bacteria were recovered in low numbers from the majority of kidneys, reflecting transfer of bacteria from the bladder to the renal pelvis. One day after inoculation, all mice were found to have positive bladder cultures, the number of bacteria ranging from $10^{2}$ to $10^{5}$ c.f.u. and the median being $7 \cdot 2 \times 10^{3}$ c.f.u. per bladder. Six of 8 mice had positive kidney cultures, 10 of 16 kidneys were infected and the number of bacteria ranged from $10^{2}$ to $10^{5}$ c.f.u., the median being $3.6 \times 10^{3}$ c.f.u. per kidney. Three days after inoculation, all mice were found to have infected bladders, the number of bacteria ranging from $10^{2}$ to $10^{6}$ c.f.u. and the median being $2.1 \times 10^{3}$ c.f.u. per bladder. Positive kidney cultures were found in 6 of 8 mice, 10 of 16 kidneys were infected, the number of bacteria ranged from $10^{2}$ to $10^{6}$ c.f.u. and the median was $6 \cdot 0 \times 10^{3}$ c.f.u. per kidney. All specimens from mice inoculated with PBS were found to be sterile $2 \mathrm{~h}, 1 \mathrm{~d}$ and $3 \mathrm{~d}$ after inoculation.

\section{Development of combined in situ hybridization and immunofluorescence assay}

For simultaneous visualization of E. coli cells and detection of type 1 fimbriae expression, an assay combining in situ rRNA hybridization and immunofluorescence was developed.

In situ hybridization was initially carried out as described previously (Poulsen et al., 1994), but the presence of SDS in the hybridization solution was found to cause non-specific binding of antibodies to the bacterial cells. After omission of SDS, the hybridization process was found to have no effect on the subsequent use of antibodies. Wash out of the oligonucleotide probe during the immunofluorescence assay was avoided by use of washing buffer with a high salt concentration and addition of the oligonucleotide probe during incubation with antibody.

The specificity of the combined assay was tested on a mixture of E. coli C175-94 and Y. enterocolitica cells. The two bacterial species are easy to distinguish by phase-contrast microscopy due to their different cell morphology. When probe EC1531, specific for E. coli $23 \mathrm{~S}$ rRNA, and antiserum against Y. enterocolitica were used in the combined assay, the two species were clearly distinguishable by fluorescence microscopy (results not shown). No Y. enterocolitica cells were stained by the CY3-labelled EC1531 probe and no E. coli cells were stained by FITC-labelled antibody, confirming that the specificity of the hybridization and the immunostaining remained intact when the two techniques were combined.

\section{Expression of type 1 fimbriae during experimental UTI}

The expression of E. coli type 1 fimbriae during UTI was investigated by use of the combined in situ hybridization and immunofluorescence assay on tissue sections and urine from infected mice sacrificed $2 \mathrm{~h}, 1 \mathrm{~d}$ and $3 \mathrm{~d}$ after inoculation.

A mean of $25 \%$ (range 15-40\%) of the E. coli C175-94 cells were found to express type 1 fimbriae when grown in vitro, as shown by immunostaining of the bacterial 

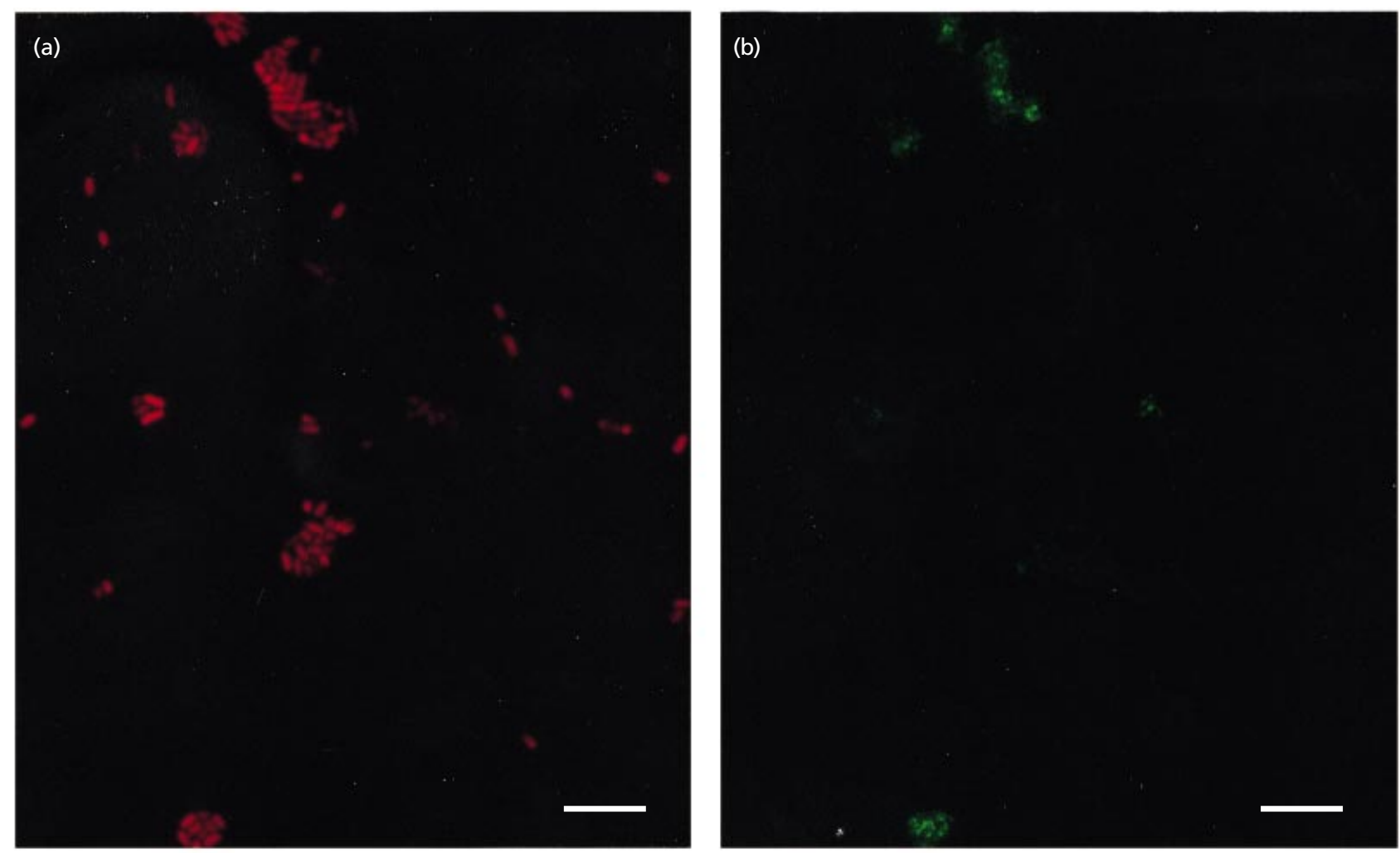

(c)

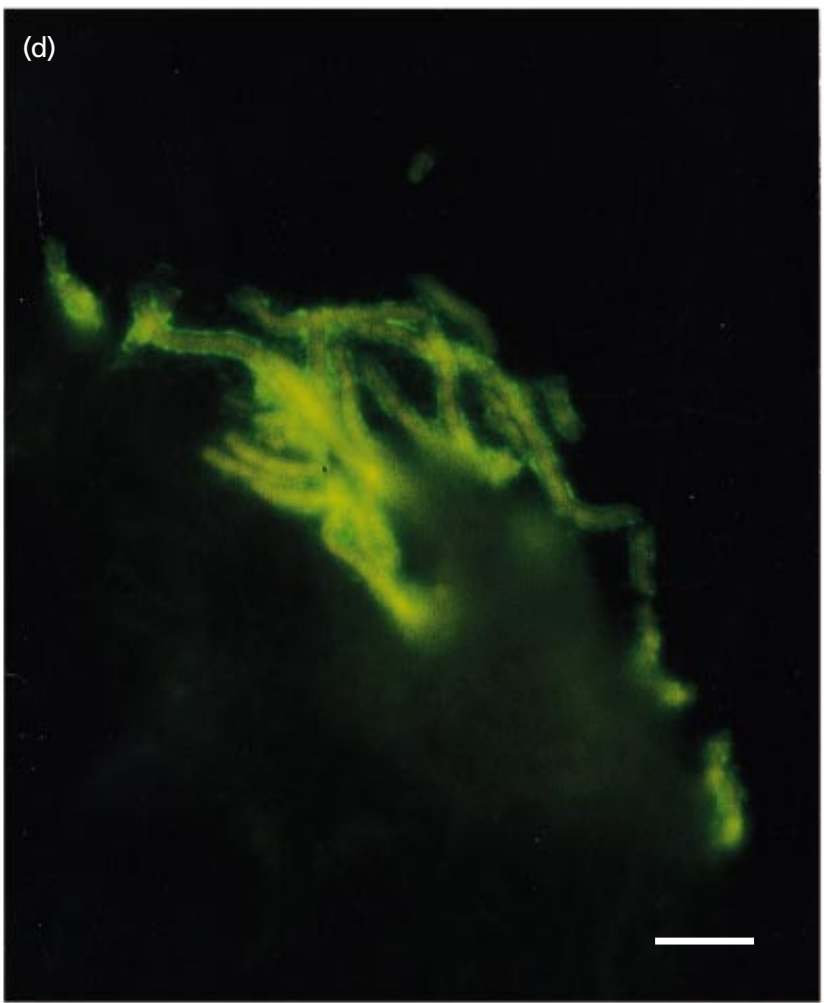

Fig. 1. Monitoring expression of type 1 fimbriae by combined in situ rRNA hybridization and immunostaining of (a, b) inoculum suspension used for infection of mice, and $(c, d)$ bladder section from mouse sacrificed $1 \mathrm{~d}$ after onset of infection. ( $a, c)$ In situ hybridization with CY3-labelled probe specific for E. coli 235 rRNA. (b, d) Immunostaining with antiserum against type 1 fimbriae. Bars: $(a, b) 10 \mu \mathrm{m}$; $(c, d) 7.5 \mu \mathrm{m}$. 
(a)

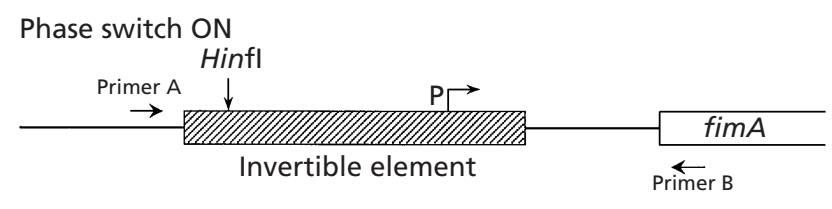

Phase switch OFF

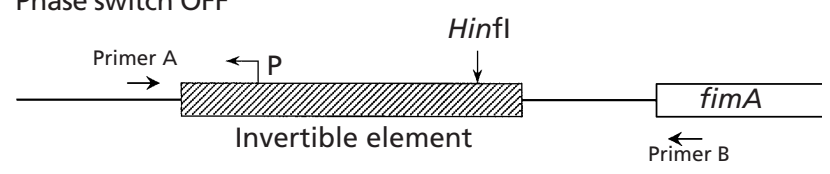

(b)
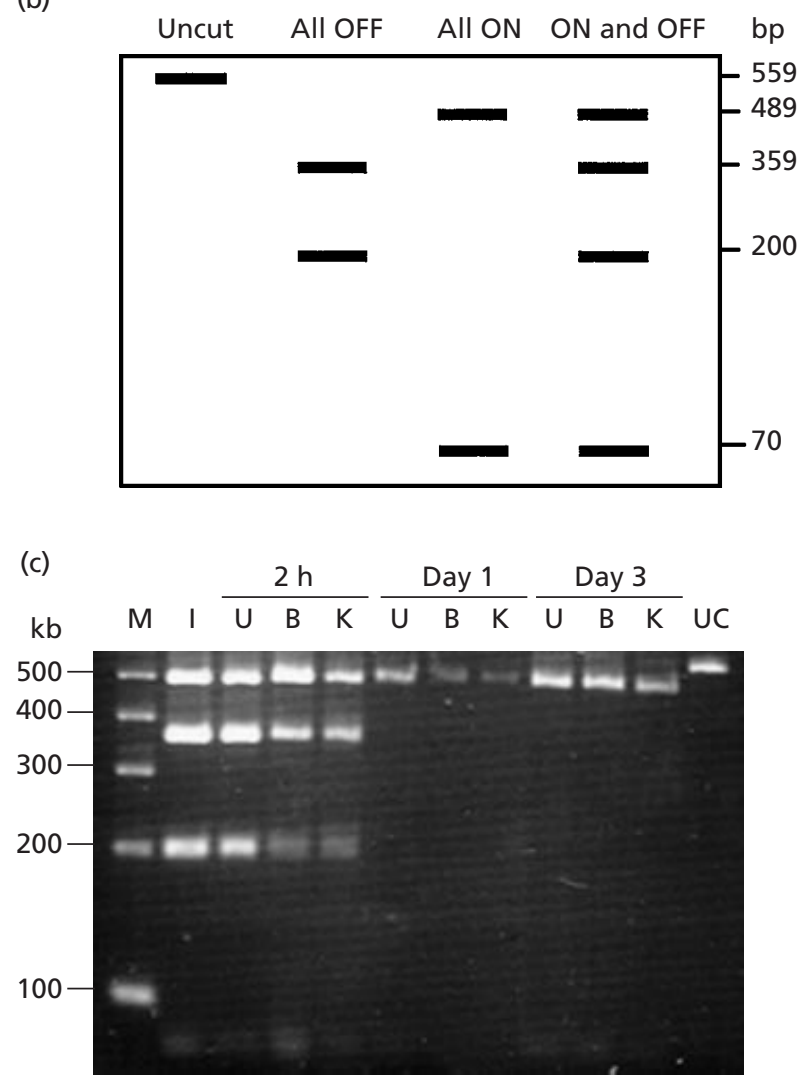

Fig. 2. Orientation of the $E$. coli type 1 fimbriae phase switch during experimental UTI. (a) Schematic representation of the phase switch region including the invertible DNA element containing the promoter $(P)$ of fimA. The orientation of the phase switch was determined by PCR amplification of the switch region followed by digestion of the PCR product with Hinfl. (b) Theoretically expected results after PCR amplification of the switch region. Due to asymmetric location of the Hinfl cleavage site within the invertible element, different fragments are obtained depending on the orientation of the switch. (c) In vivo results of PCR amplification of the fim phase switch. Orientation of the switch in inoculation suspension (I) and urine $(\mathrm{U})$, bladders (B) and kidneys (K) from mice sacrificed $2 \mathrm{~h}, 1 \mathrm{~d}$ and $3 \mathrm{~d}$ after inoculation. Lane $\mathrm{M}$, molecular size markers; lane UC, uncut PCR product.

suspension used for infection of mice (Fig. 1a, b). Likewise, the majority of bacteria present in urine $2 \mathrm{~h}$ after inoculation were found to be non-fimbriated (results not shown). In bladder sections from mice sacrificed $2 \mathrm{~h}$ after inoculation, bacteria were found randomly distributed as single cells either in contact with the bladder mucosa or free in the lumen; both fimbriated and non-fimbriated cells were observed (results not shown). Due to the low number of bacteria present in kidneys from mice sacrificed $2 \mathrm{~h}$ after inoculation, it was not possible to detect any bacteria in the kidney sections.

One and three days after onset of infection, expression of type 1 fimbriae was detected in all bacterial cells observed in urine (results not shown). In bladder sections, bacteria were observed forming microcolonies associated with the bladder epithelium (Fig. 1c, d). The microcolonies were only seen in some parts of the bladder, leaving most of the bladder mucosa uncolonized. Many of the bacterial cells observed in bladder sections were found to have undergone changes in cell morphology and were radically elongated, often with filamentous cell structures. As in urine, all bacterial cells observed in bladder sections from mice sacrificed 1 and $3 \mathrm{~d}$ after onset of infection were found to express type 1 fimbriae (Fig. 1c, d). In kidneys, bacteria were detected in the renal pelvis and were often embedded in the mucosa or in close contact with inflammatory cells, making the bacterial cells difficult to identify by phasecontrast microscopy. By use of the combined assay, bacterial cells were easily identified by in situ hybridization and the expression of type 1 fimbriae could be determined. In kidneys, all bacterial cells detected were found to express type 1 fimbriae (results not shown).

\section{Orientation of the $E$. coli fim switch during experimental UTI}

The orientation (ON or OFF) of the invertible fim switch, which drives the transcription of type 1 fimbriae genes, was determined by PCR amplification of a $559 \mathrm{bp}$ element containing the switch, followed by restriction endonuclease digestion of the PCR product (Fig. 2a). HinfI cuts the invertible DNA element asymmetrically resulting in different sized fragments depending on whether the switch is in the ON or OFF orientation (Fig. $2 b$ ). PCR was performed on urine and organ homogenates from infected mice. As expected, HinfI digestion of the PCR product from the bacterial suspension used for infection of mice resulted in four fragments, corresponding to the switch being in both the $\mathrm{ON}$ and OFF positions (Fig. 2c); i.e. both cells transcribing and not transcribing fim genes were present in the inoculum solution. Bacteria from urine, bladder and kidney samples of mice sacrificed $2 \mathrm{~h}$ after inoculation were also found to have the switch in both the ON and OFF position (Fig. 2c). In contrast, only fragments corresponding to the switch being in the ON position could be detected after digestion of PCR products from urine, bladders and kidneys of mice sacrificed 1 and $3 \mathrm{~d}$ after onset of infection (Fig. 2c); i.e. during established UTI all bacterial cells in urine, bladder and kidneys of infected animals transcribed type 1 fimbriae genes. 


\section{Influence of growth media on expression of type 1 fimbriae}

To investigate whether components of mouse urine or bladder mucus had any effect on the expression of type 1 fimbriae, overnight cultures of C175-94 grown in these media were immunostained with antiserum against type 1 fimbriae and compared with cells grown in L broth. Since mouse urine was found to be bacteriocidal for C175-94, urine dialysed against $0.9 \% \mathrm{NaCl}$ overnight was used.

No difference in the expression of type 1 fimbriae was observed between bacterial cultures grown in dialysed mouse urine, crude bladder mucus or L broth (results not shown). Approximately $25 \%$ (range $15-40 \%$ ) of the bacterial cells were found to express type 1 fimbriae; i.e. the fraction of cells expressing type 1 fimbriae in the three growth media was comparable with the fraction in the bacterial suspension used for infection of mice. The experiment was repeated three times with similar results.

\section{DISCUSSION}

Whilst animal models of UTI have been an important instrument in the assessment of virulence determinants of uropathogenic bacteria, the actual expression of specific virulence factors during infection has only been investigated in few studies. In the present study, two independent methods were used for direct determination of the expression of E. coli type 1 fimbriae in the urinary tract of mice infected with the uropathogenic E. coli C175-94. It is shown here that type 1 fimbriae are indeed expressed in vivo and that the phase switch is always towards the $\mathrm{ON}$ orientation during infection.

For simultaneous detection of E. coli cells and expression of type 1 fimbriae in tissue sections from infected mice, an assay combining in situ rRNA hybridization and immunofluorescence was developed. Even though both in situ rRNA hybridization and immunofluorescence are frequently used techniques, to our knowledge, only one study has so far described a combination of the two methods. In that work, a combination of in situ hybridization and immunofluorescence was used for the identification of Clavibacter michiganensis sepedonicus, but only in laboratory cultures (Li et al., 1997). In the present study, the specificity of the in situ hybridization and immunofluorescence assay when the two techniques were combined was confirmed by using a mixture of $E$. coli and Y. enterocolitica cells. The simultaneous identification of specific bacterial species and detection of expression of specific antigens by use of the combined assay is a useful tool in studies of complex bacterial environments, for example the gut, skin and environmental biofilms.

The expression of type 1 fimbriae during UTI was investigated by submitting urine, bladders and kidneys from mice sacrificed at different time points after inoculation with E. coli C175-94 to the combined assay of in situ hybridization and immunofluorescence. E. coli cells were detected in bladders as well as in kidneys. The presence of radically elongated bacteria in bladders has been reported previously and may be due to the high osmolarity of mouse urine (Hagberg et al., 1986). Two hours after infection, both fimbriated and nonfimbriated bacterial cells were detected in the specimens, but on days 1 and 3 after infection all bacterial cells in urine, bladders and kidneys were found to be heavily fimbriated. In contrast, approximately a quarter of the cells in the suspension used for infection of mice were fimbriated. Thus, the introduction of E. coli C175-94 into the mouse urinary tract selects for a markedly enhanced expression of type 1 fimbriae. The presence of only fimbriated bacteria in bladders and kidneys cannot be explained by specific selection for fimbriated cells via elimination of non-fimbriated cells by the flow of urine as only fimbriated cells were detected in urine 1 and $3 \mathrm{~d}$ after infection. If the presence of only fimbriated cells in bladders and kidneys was due solely to selection by enhanced adhesion of the fimbriated cells, then it would be expected that non-fimbriated cells would be detected in the urine. Since the phase switch occurs regularly, adhering fimbriated cells would occasionally give rise to non-fimbriated cells which should be present in the urine. Thus, our results show that the phase switch is directed to the ON position by an environmental signal in the urinary tract.

The above results were confirmed by PCR amplification of the invertible phase switch which drives the transcription of type 1 fimbriae. Only the switch in the $\mathrm{ON}$ position could be amplified from urine, bladders and kidneys from mice sacrificed 1 and $3 \mathrm{~d}$ after onset of infection, whilst the switch in both $\mathrm{ON}$ and $\mathrm{OFF}$ positions could be amplified from specimens from mice sacrificed $2 \mathrm{~h}$ after infection, as well as from the suspension used for inoculation of mice. Our results suggest that in the mouse urinary tract some unknown factors influence the type 1 fimbriae phase switch in such a way that the switch is always $\mathrm{ON}$, and consequently fimbriae are continuously produced. Surprisingly, neither growth in bladder mucus or mouse urine promoted type 1 fimbriae expression in C175-94 compared to when the bacteria was grown in $\mathrm{L}$ broth. However, as dialysis of mouse urine was necessary for growth of C175-94, the presence of a dialysable factor promoting type 1 fimbriae expression in urine cannot be excluded.

This study clearly indicates that expression of type 1 fimbriae is markedly enhanced during UTI, as has been shown previously for the expression of type 1 fimbriae during E. coli colonization of the gut (Krogfelt et al., 1991). Enhanced fimbrial expression during experimental UTI has also been reported for Proteus mirabilis, which expresses MR/P fimbriae (Zhao et al., 1997). Studies investigating expression of type 1 fimbriae in $E$. coli isolated directly from urine of humans suffering from UTI by the use of either immunofluorescence, electron microscopy or agglutination assays generally find that bacteria in urine produce fewer type 1 fimbriae compared to strains subcultured in vitro (Ofek et al., 1981; Harber et al., 1982; Ljungh \& Wadström, 
1983; Pere et al., 1987; Kisielius et al., 1989). However, in many of these studies, the expression of type 1 fimbriae may be affected by the processing of the samples, for example cooling and storage of the urine, or collection of urine from a specific patient group, for example patients with indwelling catheters. In bladder lavages of infected mice, bacteria were predominately fimbriated, but non-fimbriated bacteria were also present (Hultgren et al., 1985). In a recent study, it was found by use of PCR amplification of the phase switch that $2 \mathrm{~d}$ after onset of infection in mice, the phase switch is $\mathrm{ON}$ in approximately one-third of the bacteria infecting bladders and kidneys (Lim et al., 1998). However, in the suspension used for infection of mice the phase switch was almost exclusively in the OFF position, i.e. the expression of type 1 fimbriae was actually found to be enhanced during infection. It is important to mention that the strain used by Lim et al. also produced $\mathrm{P}$ fimbriae, haemolysin and $\mathrm{S}$ fimbriae (Mobley et al., 1993); the presence of these virulence factors may make the expression of type 1 fimbriae less prominent during infection of the urinary tract. Generally, it must be expected that the expression of a given virulence factor is influenced by the presence of other virulence determinants. Therefore, the patterns of fimbrial expression during infection might vary among different strains. That type 1 fimbriae are expressed during UTI is also supported by a recent study using the type 1 fimbriae adhesin (FimH) for vaccination of mice (Langermann et al., 1997). The vaccinated mice showed markedly enhanced resistance against development of UTI following inoculation with E. coli.

In conclusion, we have shown by direct detection of type 1 fimbriae as well as by assessment of the orientation of the phase switch regulating expression of type 1 fimbrial genes that expression of type 1 fimbriae is markedly enhanced during UTI caused by E. coli C175-94. The type 1 fimbriae were expressed in all E. coli cells present in the urine, the bladder and the kidneys, and the switch was directed to the $\mathrm{ON}$ orientation, suggesting regulation of the switch by an environmental factor. Thus our results indicate that type 1 fimbrial expression is important during UTI.

This is, to our knowledge, the first study where the expression and phase variation of type 1 fimbriae during infection have been assessed in vivo.

\section{ACKNOWLEDGEMENTS}

We would like to thank Don Hemantha and Ian C. Blomfield, Wake Forest University Medical Center, Winston-Salem, USA, for helpful suggestions regarding the PCR assay and Jakob Vang, The Animal Department, SSI, for excellent technical assistance. C.S. was partially supported by the Danish National Research Foundation.

\section{REFERENCES}

Abraham, J. M., Freitag, C. S., Clements, J. R. \& Eisenstein, B. I. (1985). An invertible element of DNA controls phase variation of type 1 fimbriae of Escherichia coli. Proc Natl Acad Sci USA 82, 5724-5727.
Blomfield, I. C., Calie, P. J., Eberhardt, K. J., McClain, M. S. \& Eisenstein, B. I. (1993). Lrp stimulates phase variation of type 1 fimbriation in Escherichia coli K-12. J Bacteriol 175, 27-36.

Connell, H., Agace, W., Klemm, P., Schembri, M., Mårild, S. \& Svanborg, C. (1996). Type 1 fimbrial expression enhances Escherichia coli virulence for the urinary tract. Proc Natl Acad Sci USA 93, 9827-9832.

Donnenberg, M. S. \& Welch, R. A. (1996). Virulence determinants of uropathogenic Escherichia coli. In Urinary Tract Infections: Molecular Pathogenesis and Clinical Management, pp. 135-174. Edited by H. L. T. Mobley \& J. W. Warren. Washington, DC: American Society for Microbiology.

Fujita, K., Yamamoto, T., Yokota, T. \& Kitagawa, R. (1989). In vitro adherence of type 1-fimbriated uropathogenic Escherichia coli to human urethral mucosa. Infect Immun 57, 2574-2579.

Gally, D. L., Bogan, J. A., Eisenstein, B. I. \& Blomfield, I. C. (1993). Environmental regulation of the fim switch controlling type 1 fimbrial phase variation in Escherichia coli K-12: effects of temperature and media. J Bacteriol 175, 6186-6193.

Hagberg, L., Jodal, U., Korhonen, T. K., Lidin-Janson, G., Lindenberg, U. \& Svanborg Edén, C. (1981). Adhesion, hemagglutination, and virulence of Escherichia coli causing urinary tract infections. Infect Immun 31, 564-570.

Hagberg, L., Hull, R., Hull, S., Falkow, R., Freter, R. \& Svanborg Edén, C. (1983). Contribution of adhesion to bacterial persistence in the mouse urinary tract. Infect Immun 40, 265-272.

Hagberg, L., Lam, J., Svanborg-Edén, C. \& Costerton, J. W. (1986). Interaction of a pyelonephritogenic Escherichia coli strain with the tissue components of the mouse urinary tract. J Urol 136, $165-172$.

Harber, M. J., Chick, S., Mackenzie, R. \& Asscher, A. W. (1982). Lack of adherence to epithelial cells by freshly isolated urinary pathogens. Lancet ii, 586-588.

Hultgren, S. J., Porter, T. N., Schaeffer, A. J. \& Duncan, J. L. (1985). Role of type 1 pili and effects of phase variation on lower urinary tract infections produced by Escherichia coli. Infect Immun 50, 370-377.

Kisielius, P. V., Schwan, W. R., Amundsen, S. K., Duncan, J. L. \& Schaeffer, A. J. (1989). In vivo expression and variation of Escherichia coli type 1 and $\mathrm{P}$ pili in the urine of adults with acute urinary tract infections. Infect Immun 57, 1656-1662.

Klemm, P. (1986). Two regulatory genes, fimB and fimE, control the phase variation of type 1 fimbriae in Escherichia coli. EMBO J 5, 1389-1393.

Klemm, P. \& Krogfelt, K. A. (1994). Type 1 fimbriae of Escherichia coli. In Fimbriae: Adhesion, Genetics, Biogenesis, and Vaccines, pp. 9-26. Edited by P. Klemm. Boca Raton, FL: CRC Press.

Krogfelt, K. A. \& Klemm, P. (1988). Investigation of minor components of Escherichia coli type 1 fimbriae: protein chemical and immunological aspects. Microb Pathog 4, 231-238.

Krogfelt, K. A., McCormick, B. A., Burghoff, R. L., Laux, D. C. \& Cohen, P. S. (1991). Expression of Escherichia coli F-18 type 1 fimbriae in the streptomycin-treated mouse large intestine. Infect Immun 59, 1567-1568.

Langermann, S., Palaszynski, S., Barnhart, M. \& 8 other authors (1997). Prevention of mucosal Escherichia coli infection by FimHadhesin-based systemic vaccination. Science 276, 607-611.

Li, X., De Boer, S. H. \& Ward, L. J. (1997). Improved microscopic identification of Clavibacter michiganensis subsp. sepedonicus cells by combining in situ hybridisation with immunofluorescence. Lett Appl Microbiol 24, 431-434.

Lim, J. K., Iv, N. W. G., Zhao, H., Johnson, D. E., Keay, S. K. \& 
Mobley, H. L. T. (1998). In vivo phase variation of Escherichia coli type 1 fimbrial genes in women with urinary tract infection. Infect Immun 66, 3303-3310.

Ljungh, Å. \& Wadström, T. (1983). Fimbriation of Escherichia coli in urinary tract infections. Comparisons between bacteria in the urine and subcultured bacterial isolates. Curr Microbiol 8, 263-268.

Mobley, H. L. T., Jarvis, K. G., Elwood, J.P., Whittle, D. I., Lockatell, C. V., Russell, R. G., Johnson, D. E., Donnenberg, M. S. \& Warren, J. W. (1993). Isogenic P-fimbrial deletion mutants of pyelonephritogenic Escherichia coli: the role of $\alpha \mathrm{Gal}(1-4) \beta \mathrm{Gal}$ binding in virulence of a wild-type strain. Mol Microbiol 10, 143-155.

Mulvey, M. A., Lopez-Boado, Y. S., Wilson, C. L., Roth, R., Parks, W. C., Heuser, J. \& Hultgren, S. J. (1998). Induction and evasion of host defences by type 1-pilated uropathogenic Escherichia coli. Science 282, 1494-1497.

Newman, J. V., Burghoff, R. L., Pallesen, L., Krogfelt, K. A., Kristensen, C. S., Laux, D. C. \& Cohen, P. S. (1994). Stimulation of Escherichia coli F-18 Col- type 1 fimbriae synthesis by leuX. FEMS Microbiol Lett 122, 281-287.

Ofek, I., Mosek, A. \& Sharon, N. (1981). Mannose-specific adherence of Escherichia coli freshly excreted in the urine of patients with urinary tract infections, and of isolates subcultured from the infected urine. Infect Immun 34, 708-711.

Old, D. C. \& Duguid, J. P. (1970). Selective outgrowth of fimbriated bacteria in static liquid medium. J Bacteriol 103, 447-456.

Olsen, P. B., Schembri, M. A., Gally, D. L. \& Klemm, P. (1998). Differential temperature modulation by H-NS of the fimB and fimE recombinase genes which control the orientation of the type 1 fimbrial phase switch. FEMS Microbiol Lett 162, 17-23.

Orndorff, P. E. \& Bloch, C. A. (1990). The role of type 1 pili in the pathogenesis of Escherichia coli infections: a short review and some new ideas. Microb Pathog 9, 75-79.

Ørskov, l., Ørskov, F. \& Birch-Andersen, A. (1980). Comparison of Escherichia coli fimbrial antigen F7 with type 1 fimbriae. Infect Immun 27, 657-666.

Pere, A., Nowicki, B., Saxén, H., Siitonen, A. \& Korhonen, T. K. (1987). Expression of $P$, type 1, and type-1C fimbriae of Escherichia coli in the urine of patients with acute urinary tract infection. J Infect Dis 156, 567-574.
Poulsen, L. K., Lan, F., Kristensen, C. S., Hobolth, P., Molin, S. \& Krogfelt, K. A. (1994). Spatial distribution of Escherichia coli in the mouse large intestine inferred from rRNA in situ hybridisation. Infect Immun 62, 5191-5194.

Reid, G. \& Sobel, J. D. (1987). Bacterial adherence in the pathogenesis of urinary tract infection: a review. Rev Infect Dis $\mathbf{9}$, 470-486.

Roesch, P. L. \& Blomfield, I. C. (1998). Leucine alters the interaction of the leucine-responsive regulatory protein (Lrp) with the fim switch to stimulate site-specific recombination in Escherichia coli. Mol Microbiol 27, 751-761.

Schaeffer, A. J., Schwan, W. R., Hultgren, S. J. \& Duncan, J. L. (1987). Relationship of type 1 pilus expression in Escherichia coli to ascending urinary tract infections in mice. Infect Immun 55, 373-380.

Schwan, W. R., Seifert, H. S. \& Duncan, J. L. (1992). Growth conditions mediate differential transcription of fim genes involved in phase variation of type 1 pili. J Bacteriol 174, 2367-2375.

Sharma, S., Harjai, K. \& Mittal, R. (1991). Enhanced siderophore production and mouse kidney pathogenicity in Escherichia coli grown in urine. J Med Microbiol 35, 325-329.

Sobel, J. D. (1991). Bacterial etiologic agents in the pathogenesis of urinary tract infections. Med Clin N Am 75, 253-273.

Sokurenko, E., Courtney, H., Ohman, D., Klemm, P. \& Hasty, D. (1994). FimH family of type 1 fimbrial adhesins: functional heterogeneity due to minor sequence variations among fim $\mathrm{H}$ genes. J Bacteriol 176, 748-755.

Sokurenko, E. V., Chesnokova, V., Dykhuizen, D. E., Ofek, I., Wu, X., Krogfelt, K. A., Struve, C., Schembri, M. A. \& Hasty, D. L. (1998). Pathogenic adaptation of Escherichia coli by natural variation of the FimH adhesin. Proc Natl Acad Sci USA 95, 8922-8926.

Virkola, R. (1987). Binding characteristics of Escherichia coli type 1 fimbriae in the human kidney. FEMS Microbiol Lett 40, 257-262.

Zhao, H., Li., X., Johnson, D. E., Blomfield, I. \& Mobley, H. L. T. (1997). In vivo phase variation of $M R / P$ fimbrial gene expression in Proteus mirabilis infecting the urinary tract. Mol Microbiol 23, 1009-1019.

Received 11 February 1999; revised 10 June 1999; accepted 1 July 1999. 